\section{Mulheres de Camaragibe: representação social sobre a vulnerabilidade feminina em tempos de AIDS}

\author{
Women from Camaragibe: \\ social representation of women's \\ vulnerability in times of AIDS
}

Ana Maria Guedes do Nascimento 1 Constança Simões Barbosa 2 Benedito Medrado 3

1,2 Departamento de Parasitologia. Centro de Pesquisas Aggeu Magalhães da Fundação Oswaldo Cruz. Recife, PE, Brasil. CEP: 50.670-420. E-mail: cbarbosa@cpqam.fiocruz.br 3 Instituto Papai. Rua Mardônio Nascimento, 119-1 Várzea. Recife, PE, Brasil.

\begin{abstract}
Objectives: to understand the social representation of poor married women in relation to AIDS. This understanding will contribute to fight the epidemics in a way more in tune with reality.

Methods: sixteen interviews were accomplished in poor women with stable marriages. The interviews were taped, transcribed and grouped according to evaluation and analysis criteria. Analysis was performed through a hermeneutic proposal related to the interpretation of underlying meanings.

Results: there was an increase of women's vulnerability concerning HIV/AIDS based on the social awareness these women have of AIDS, considering that their perception eventually provides them with a false immunity sensation for they do not have the profile which they imagine carry the virus or the disease.

Conclusions: current epidemiological AIDS profile points towards women as the target of infection, particularly through sexual relations which are established by gender relations. They regard AIDS as a distant evil, and if close, not related to them, and when it does it is legitimated by being "the deed of God" or stemming from their own roles as wives.
\end{abstract}

Key words Acquired Immunodeficiency syndrome, Vulnerability, Women

\section{Resumo}

Objetivos: compreender a representação social que mulheres casadas, em situação de pobreza, possuem acerca da AIDS. Dessa forma, se espera contribuir para que o enfrentamento da epidemia se dê de forma mais sintonizada com a realidade em que essa acontece.

Métodos: foram realizadas 16 entrevistas, com mulheres em situação de pobreza, com relação conjugal estável. Essas entrevistas foram gravadas, transcritas e agrupadas segundo critérios de avaliação e análise. A análise foi feita com base na proposta da hermenêutica, que se refere à leitura das entrelinhas.

Resultados: foi observado um aumento da vulnerabilidade feminina frente à infecção pelo HIV/AIDS, baseado na representação social que essas mulheres têm da AIDS, visto que suas percepções acabam por lhes fornecer uma falsa sensação de imunidade, pois elas não se encaixam dentro do perfil que imaginam como sendo de quem apresenta o vírus ou a própria doença.

Conclusões: o perfil epidemiológico atual da AIDS aponta a mulher como alvo da infecção. Isso ocorre principalmente através das relações sexuais, que são ditadas pelas relações de gênero. Para elas a AIDS é um mal distante; se próximo, não lhes pertence, se lhes pertence é legitimado por ser "obra de Deus" ou por ser próprio do papel de esposa.

Palavras-chave AIDS, Vulnerabilidade, Mulheres 


\section{Introdução}

O preconceito, a falta de informação, o "não é comigo" compuseram as características mais importantes que acompanharam o surgimento dos primeiros casos de AIDS no Brasil e, de certa forma, estendem-se até hoje formando idéias e representações que foram se sobrepondo umas às outras. Avanços científicos e tecnológicos contribuíram para o desenvolvimento de recursos diagnósticos, prognósticos e terapêuticos mais eficazes, sem que isso correspondesse à diminuição da incidência e prevalência dos casos. A AIDS deixou de ser "privilégio" de grupos para atingir populações diversas.

O período compreendido entre 1981 e 1984 corresponde aos primeiros contatos com a "nova entidade clínica", que veio chamar a atenção dos serviços de saúde, principalmente dos centros de investigação epidemiológica, como o Center for Disease Control (CDC), buscando-se de imediato os fatores de risco associados e traçando-se um perfil epidemiológico e clínico. Sendo, então, detectado um estado de fragilidade no sistema imunológico dos doentes, começou a se difundir o termo Síndrome da Imunodeficiência Adquirida (SIDA), que se tornou mundialmente conhecida pela sua sigla em inglês, AIDS (Acquired Immunodeficiency Syndrome). O surgimento de casos entre receptores de sangue, hemoderivados e em usuários de drogas injetáveis levou os pesquisadores a procurarem por um agente infeccioso. Como havia uma incidência quase exclusiva entre os "gays", promoveram-se buscas por uma ligação entre a homossexualidade e a AIDS. Havia então um fator de risco associado a grupos aparentemente delimitados. ${ }^{1,2}$

Utilizou-se o termo "grupo de risco", tendo em vista que a incidência de AIDS aparentemente privilegiava grupos específicos como homossexuais masculinos, hemofílicos e usuários de drogas intravenosas. Essa idéia só veio a ser repensada após o isolamento do Human Immunodeficiency Virus (HIV) em 1983 quando, então, surgiram evidências de que a epidemia não se limitava a grupos ou a regiões, estabelecendo o caráter transmissível da doença. ${ }^{3}$

Posteriormente, a expressão "comportamento de risco" começou a ser difundido tanto para eliminar o caráter discriminatório da expressão anteriormente utilizada, como pela percepção de que a infecção se expandia para além daqueles grupos. Era o momento da instalação da culpabilidade individual e o conseqüente estímulo à prevenção. Ainda assim, a identificação dos primeiros casos entre homossexuais masculinos norte-americanos estabeleceu um vínculo entre a doença e a homossexualidade que, até hoje, não foi completamente rompido. No final dos anos 80, observou-se que os programas de incentivo à prevenção de base individual não alcançavam o efeito esperado na contenção da epidemia. Outros aspectos no campo social, cultural, econômico e político, até então pouco considerados, passaram também a ser envolvidos. ${ }^{4-6}$

No Brasil começaram a ser identificados os primeiros casos de AIDS no início dos anos 80, e hoje não há uma epidemia uniforme, mas um conjunto de microepidemias regionais, sendo essa característica o reflexo do tamanho e da diversidade sócio-cultural do país. Essa diversidade, associada ao dinamismo de disseminação da infecção, dificultou e dificulta o entendimento da trajetória da doença, como também, sua prevenção e controle. No entanto, sabe-se que atualmente acontece uma maior disseminação proporcional em mulheres, no Brasil e em todo o mundo. ${ }^{7}$

Algumas tendências no padrão de infecção no Brasil têm sido observadas. Uma delas diz respeito ao comportamento espacial da epidemia, a interiorização; outra fala da heterossexualização da epidemia. Na primeira década da história da AIDS, a epidemia era basicamente restrita às áreas metropolitanas da região Sudeste, aos homossexuais masculinos, aos hemotransfundidos e aos usuários de drogas injetáveis (UDI). Associada à tendência heterossexual da epidemia, existe a feminização, que aponta uma maior exposição da mulher, seja por uma maior vulnerabilidade biológica, uma menor detenção de poder nas decisões que envolvem a vida sexual e reprodutiva, um envolvimento emocional diferenciado, em relação às parcerias, ou, ainda, pela crença de invulnerabilidade feminina, visto que inicialmente a mulher não era incluída nos chamados "grupos de risco". Uma quarta tendência fala da pauperização da doença, no sentido de haver uma incidência maior de casos de AIDS nas populações de menor nível socioeconômico. ${ }^{7}$

Dados do Ministério da Saúde8 confirmam essas tendências. Observa-se entre os homens, no período de 1994-1998, um percentual de crescimento de $10,2 \%$ das notificações, enquanto nas mulheres o crescimento foi na ordem de $75,3 \%$ no mesmo período. (Tabela 1) Em relação às subcategorias de exposição, observou-se que $43,5 \%$ são heterossexuais, $21,8 \%$ são homo/bissexuais e $12,1 \%$ são usuários de drogas injetáveis. Enquanto que em anos anteriores a exposição heterossexual ao HIV era mínima em relação à categoria homo/bissexual, no período de 1994-1998, os casos com exposição heterossexual apresentaram um crescimento de $113 \%$ e os casos de exposição homo/bissexuais tiveram um acréscimo de 8,6\%. Dentre os usuários de drogas injetáveis, observou-se um decréscimo de $18 \%$ no número de casos, no mesmo período. 8 (Tabela 2 ) 
Distribuição dos casos de AIDS segundo sexo e ano de diagnóstico, em porcentagem. Brasil, 1983-2001.

\begin{tabular}{lccccc}
\hline Sexo & $1983-1990$ & $1991-1995$ & 1996-1999 & 2000-2001 & Total \\
\hline Masculino & 13,8 & 41,1 & 39,2 & 5,9 & 100 \\
Feminino & 6,1 & 33,6 & 51,5 & 8,8 & 100 \\
Média do período & 9,9 & 37,3 & 45,4 & 7,4 & 100 \\
\hline
\end{tabular}

Fonte: Adaptada de: Ministério da Saúde; 2001. 8

Tabela 2

Distribuição dos casos de AIDS, segundo ano de diagnóstico e categoria de exposição hierarquizada, em porcentagem. Brasil, 1983-2001.

\begin{tabular}{lccccc}
\hline Sexo & $1983-1990$ & $1991-1995$ & 1996-1999 & 2000-2001 & Total \\
\hline Sexual & 56,6 & 49,22 & 54,9 & 67,2 & 53,5 \\
$\quad$ Homo/bissexual & 46,6 & 29,14 & 21,11 & 21,11 & 27,0 \\
$\quad$ Heterossexual & 9,9 & 20,1 & 33,8 & 46,1 & 26,6 \\
Sangüínea & 23,6 & 25,1 & 16 & 12,7 & 20,1 \\
Perinatal & 1,8 & 2,7 & 3,3 & 1,9 & 23,6 \\
Ignorada & 18,1 & 23,0 & 25,9 & 6,2 & 100,0 \\
Total & 11,8 & 39,3 & 42,3 & 6 & \\
\hline
\end{tabular}

Fonte: Adaptada: Ministério da Saúde; 2001.8

$\mathrm{E}=$ Categorias de exposição

No final da década de 80 , a realidade se mostrou bem mais complexa do que se imaginava. A crença de que o HIV e a AIDS fossem restritos a grupos bem definidos, reforçou preconceitos sobre sexo considerado imoral, em vez de destacar o que há de comum em todos os comportamentos sexuais, nos quais sexo desprotegido pode levar à infecção, seja em homo ou heterosexuais, em casados ou solteiros. A mobilização de grupos politicamente organizados, a notificação compulsória dos casos de AIDS, entre outros fatores, fez com que houvesse um redimensionamento da AIDS no Brasil.9

Galvão ${ }^{5}$ aponta um período da história da AIDS no Brasil, onde várias foram as declarações de setores importantes da saúde pública brasileira que desnortearam a compreensão da expansão da epidemia de AIDS. Em 1985, o então Ministro da Saúde, afirmou que se fosse feito um trabalho de esclarecimento entre os homossexuais para que não fizessem doação de sangue, o risco por essa via cairia a zero. Ainda no início da década de 90, veiculavam declarações em jornais, feitas por médicos infectologistas, que punham em dúvida o poder de transmissão da doença da mulher para o homem. 5

Por razões como essas é que, até pouco tempo, o sexo não era especificado nas estatísticas de HIV/AIDS. Isso fez com que os riscos das mulheres se tornassem menos visíveis. Essa forma de visualizar a situação deixa a idéia de que homens que fazem sexo com homens (HSH) só sejam infectados por outros homens. Não se considera que a infecção pode ter sido instalada por uma categoria de homens que fazem sexo com mulheres e são considerados exclusivamente heterossexuais. No entanto, por terem práticas homossexuais eventuais e heterossexuais clandestinas, disseminam de forma silenciosa a infecção entre as mulheres esposas, através da prática de um sexo construído no imaginário coletivo como seguro. 10

Além disso, existe a idéia de que AIDS é doença de mulher promíscua, fazendo com que o pensa- 
mento hegemônico sobre mulher/AIDS promova uma mistura contraditória de excesso e falta de visibilidade, em detrimento das próprias mulheres, já que muitas mulheres não se vêem como tendo comportamentos de risco. Também as mulheres, em geral as mais pobres e com grau de escolaridade pouco expressivo, não tendo acesso a informações adequadas ficam dependentes exclusivamente dos conhecimentos da sabedoria popular, o que as leva a criarem fantasias e medos em relação ao próprio corpo. 9,11

Ainda assim, mulheres que possuem um papel social definido de esposa, mesmo que já infectadas pelo vírus, não se identificam com os chamados grupos de risco e a AIDS torna-se pensada como doença do "outro". Elas procuram se diferenciar desse "outro" legitimando sua infecção no fato de terem sido infectadas através de um parceiro fixo, não se preocupando com a forma de infecção desse parceiro, já que práticas extraconjugais, uso esporádico de algum tipo de droga e relações homossexuais eventuais fazem parte do imaginário sobre o universo masculino. 12

A mudança do perfil epidemiológico, com a inclusão crescente do sexo feminino, exigiu um debate com novo dimensionamento e remete a um novo conceito, que pode ser utilizado para a compreensão da disseminação do vírus: a vulnerabilidade. O termo provém da área dos Direitos Humanos e começa a ser difundido mais fortemente no campo da saúde com o surgimento da AIDS e com a compreensão de que os conceitos epidemiológicos de grupo de risco e comportamento de risco não conseguiram alcançar respostas para a evolução da epidemia. ${ }^{1,13,14}$

A discussão no campo das relações de gênero se torna crucial para o entendimento de como, ao longo dos anos, se deu o incremento da participação feminina nos números da epidemia e traz consigo questões outras, como a falta de proteção para com a mulher, evidenciadas por limitações tanto nas relações interpessoais, como na condição econômica e social. ${ }^{15}$

Um dos meios de compreender como acontecem as relações de poder num contexto de sexualidade e gênero seria a partir da característica patriarcal e agrária do Brasil, onde foram criadas imagens e modelos para homens e mulheres. Dentro desses modelos, categorias sexuais foram construídas no intuito de definir e sustentar funções desempenhadas pelos sexos: homem e mulher; macho e fêmea; esposo e esposa. Essas compreensões irão configurar um emaranhado de representações que, no Brasil contemporâneo, influenciam as formas de relações sociais entre os sexos. 16
Dentre as várias questões que envolvem gênero está a negociação sexual. Hoje essa prática está vinculada à proteção e preservação da saúde, antes, porém, a idéia de negociação sexual não apresentava reconhecimento positivo entre o público, já que quem negociava sexo eram prostitutas, michês, cafetões e cafetinas. A partir de estratégias para enfrentamento da epidemia de AIDS é que esse tema se torna uma questão importante, se ampliando quando a exposição heterossexual ganha grandes proporções, principalmente quando se trata da exposição feminina.17

A negociação sexual é uma prática que pressupõe a existência de algo a ser barganhado, uma disputa por algum benefício entre duas partes, onde em princípio uma delas não está de acordo com os meios de barganha. A desvantagem das mulheres nessa medida interventora é verificada quando se percebe que a principal medida preventiva negociável é o uso da "camisinha", um método masculino. Várias questões irão restringir a exigência do uso da "camisinha" pelo parceiro, uma vez que usar ou não preservativo não é só uma escolha individual, mas uma escolha que depende diretamente da aceitação ou não do parceiro e implica custos e benefícios. 14,18

Dentre as restrições na solicitação para uso da "camisinha" estão as representações de amor e sexualidade que homens e mulheres apresentam em relação aos seus encontros sexuais e que se contrapõem a exigências dessa ordem. Outra questão é o pouco hábito de discussão sobre sexo entre os parceiros, já que contracepção é culturalmente um dever feminino e as DSTs passam muitas vezes desapercebidas pelos casais e serviços de saúde. Outros fatores ainda compõem a lista de dificuldades para o uso ou não do cóndon masculino, como: a possibilidade de se colocar em jogo toda a relação afetiva a partir de dúvidas sobre fidelidade e a exposição do poder de decisão do parceiro, que geraria o medo de reações violentas por parte destes, já que são eles que usam o preservativo. 15,18

O encorajamento para redução do número de parceiros e o tratamento de doenças sexualmente transmissíveis, também são tidas como práticas preventivas, mas, culturalmente, quem possui um número maior de parceiros são os homens e quem mais busca serviços de saúde são as mulheres. Outros fatores como: o perfil epidemiológico da AIDS inicialmente; a demora no diagnóstico preciso; a não inserção de mulheres nos primeiros estudos acerca da epidemia, como também as propagandas de incentivo à prevenção focalizando AIDS/grupo de risco, além de discriminar, incrementaram essa crença da invulnerabilidade feminina. $14,18,19$ 


\section{Representação social e AIDS}

De acordo com Nóbrega existe uma dificuldade em se definir representações sociais por essas designarem um grande número de fenômenos e dessa forma estarem presentes em vários campos da ciência, como na Sociologia, na Antropologia e na Psicologia. O que unifica a definição é o fato de que "... toda representação é sempre uma representação de alguma coisa ou de alguém", para isso, utilizando-se da idéia do símbolo. 20

Através dessa atividade de representar, o indivíduo constrói uma nova realidade de seu mundo, dando-lhe novos significados que o conduzem. Essa interpretação da realidade é traduzida como um conjunto lógico de pensamento que vai constituir a visão de mundo para uma certa coletividade. 21

As representações sociais como fenômeno são uma forma de saber gerada a partir do senso comum. As Teorias das Representações Sociais são uma forma possível de estudar o conhecimento do senso comum, considerando o sujeito como parte de um conjunto indissociável com objeto e sociedade. A partir dessa perspectiva, busca-se compreender processos que ocorrem em contextos históricos e sócio-culturais precisos, na construção do senso comum. 22

Para Moscovici, 23 representações sociais são um conjunto de conceitos e explicações originadas no cotidiano, dentro das comunicações interpessoais podendo, ser equivalente aos mitos e crenças das sociedades tradicionais, ou ainda uma versão contemporânea do senso comum.

Apesar de haver estudos anteriores acerca das representações, foi só a partir de 1961 que Moscovici retoma o estudo da teoria. Para Moscovici, os primeiros estudiosos como Durkheim, (o primeiro estudioso a tratar desse conceito meio século atrás) que sugeriram o conceito de representação como uma forma de conhecimento, estavam mais preocupados com seu caráter coletivo e estático do que com seu conteúdo e dinâmica. Havia uma necessidade de reconhecer a oposição entre coletivo e individual e por isso mesmo o termo Representação Social não foi utilizado, mas Representação Coletiva e Representação Individual, onde o substrato da Representação Coletiva era a sociedade e, por assim ser, impessoal e permanente, enquanto na individual o substrato era a própria consciência de cada um, portanto flutuante e subjetiva. Faltava então um elo entre o indivíduo e a sociedade que só mais tarde foi dado por Moscovici.24,25

Inserir representação social no contexto da AIDS significa construir formas de pensar e explicar a
AIDS como objeto social, uma vez que o estudo permite apreender como os grupos sociais entendem determinados fenômenos. Historicamente, doenças epidêmicas e incuráveis têm sido tratadas como problema e responsabilidade do "outro" e associadas a práticas construídas como "estrangeiras". 26

As representações que se tem da AIDS ainda hoje são, em sua maioria, frutos das primeiras informações noticiadas, que apresentavam à sociedade uma doença grave, de evolução rápida, cuja patogenia era desconhecida e letal, onde suas vítimas eram, principalmente, homossexuais masculinos de grandes centros urbanos, onde a AIDS era um objeto social novo, estranho e ameaçador. A AIDS é então ligada a uma condição do "outro" e a uma condição "estrangeira", como meio de defesa, que desvia a atenção da ameaça colocada pela AIDS ao "eu" centra seu olhar sobre o "outro", "ameaçado e ameaçador". Existem diferenças nas Representações Sociais que diferentes indivíduos apóiam, esse fato pode explicado devido às diferentes posições sociais que cada indivíduo ocupa. 26

O presente estudo busca compreender a representação social que a categoria agora mais exposta mulheres casadas - tem da AIDS. Nesse sentido espera-se contribuir para que o enfrentamento da epidemia se faça de forma mais sintonizada com a realidade em que essa acontece, dessa forma, esse estudo exige uma abordagem qualitativa de caráter exploratório.

\section{Métodos}

A localidade escolhida foi o bairro de Alberto Maia, em Camaragibe, Região Metropolitana de Recife (RMR). Situado a $16 \mathrm{Km}$ da capital, na zona da Mata norte do estado de Pernambuco, Brasil, possui um território de $52,9 \mathrm{Km}^{2}$ e uma população de 121.441 habitantes. A atividade econômica básica se restringe ao setor de serviços públicos e ao comércio informal, sendo grande parte da mão de obra aproveitada em trabalhos na capital. Isto leva a uma dependência do transporte coletivo, gerando dificuldades principalmente para as pessoas que não podem se ausentar por longo período de seus lares. Apresenta uma política de saúde voltada para a família e para a saúde materno-infantil, através do Programa de Agentes Comunitários de Saúde (PACS) e do Programa de Saúde da Família (PSF).

A amostra foi delimitada através dos critérios de exclusão e inclusão. Foram selecionadas mulheres, com relação conjugal estável, dependentes economicamente do marido, cuja renda não fosse superior a 
dois salários mínimos. Ao longo do trabalho de campo, foram recrutadas, através de visitas domiciliares das ACS, 36 mulheres, das quais foram entrevistadas 16. Além dessas mulheres, as ACS também constituíram fonte de informações, embora não tenham sido realizadas entrevistas com esse grupo, visto que suas informações foram a partir dos seus olhares, de como visualizavam os vários aspectos da comunidade e não da temática AIDS-vulnerabilidade.

A consulta documental por meio do acesso desde fichas individuais dos pacientes do posto de saúde, até registros demográficos e epidemiológicos do bairro, foi facultada pela Secretaria de Saúde do Município, o que incluiu também o acesso a informações de trabalhos realizados por outros pesquisadores na comunidade. A observação participante por meio das visitas domiciliares, em companhia das ACS, foi registrada em um diário de campo. Foi utilizada a entrevista não-estruturada, por se tratar de um instrumento teórico-metodológico que permite, segundo Minayo (2000:122)24 " .. trabalhar com o universo de significados, motivos, aspirações, crenças, valores e atitudes, o que corresponde a um espaço mais profundo das relações, dos processos e dos fenômenos."

Houve a elaboração de um roteiro para apreender sistemas de valores e de normas de representações, onde os principais pontos levantados foram: história afetiva e conjugal, iniciação sexual, informação sobre sexo, informação sobre DST, informação sobre AIDS, prevenção das DST/AIDS, concepções sobre a AIDS e susceptibilidade/vulnerabilidade às DST/AIDS. O roteiro foi elaborado no sentido de orientar uma "conversa", visando apreender o ponto-de-vista dos sujeitos entrevistados, ou seja, permitiu-se o livre discurso e ao mesmo tempo o delineamento da conversa, no sentido de manter a entrevista sintonizada com os objetivos da pesquisa. Ao todo, foram realizadas 16 entrevistas, com duração média de 45 minutos, gravadas e, posteriormente, transcritas e agrupadas, segundo critérios propostos por Minayo, 25 que partem da ordenação dos dados, passando por uma classificação dos mesmos, para finalizar na análise como um todo.

A análise dos dados foi baseada na abordagem hermenêutica, que se refere à leitura das entrelinhas das falas dos atores entrevistados e traz para o primeiro plano, no tratamento dos dados, as condições do dia-a-dia, promovendo o esclarecimento sobre as estruturas desse cotidiano, e assim alcançar a compreensão do significado da representação social que a categoria em estudo faz da AIDS, dos seus determinantes e verificando se, a partir disso, há ou não um incremento da sua vulnerabilidade.

\section{Resultados e Discussão}

Iniciamos percebendo Camaragibe em suas peculiaridades, que a faz ser ao mesmo tempo cidade interiorana e metropolitana. Interiorana pela disposição geográfica, pela pequena importância política e econômica na região, pelo seu aspecto bucólico e agrário; metropolitana por se localizar às margens da capital, Recife, compondo uma região metropolitana, a Região Metropolitana do Recife (RMR), pelo caos urbano próprio das metrópoles brasileiras.

As relações de Camaragibe com a cidade vizinha, Recife, sempre foram estreitas. Pode-se perceber esse vínculo pela forma como as pessoas tratam a dinâmica de ir e vir entre as cidades, como se estivessem indo de um bairro mais distante ao centro urbano, onde há maior distribuição de produtos e serviços. Esses laços foram, pouco a pouco, se fortalecendo pelas facilidades que o transporte coletivo trouxe, proporcionando uma redução nas distâncias entre esses centros.

Nesse lugar, encontramos as mulheres, fontes de informação de nosso estudo, fontes da nossa inquietação na tentativa de desvendar as representações que possuem da AIDS, como pensam e como vêem a AIDS, em suas vidas. Vale registrar que mergulhamos num tema pouco explorado, e que muitas vezes não se mostrava prioritário na vida dessas pessoas, já que questões como alimentação e moradia, básicas em qualquer contexto humano, tornam-se os eixos centrais de preocupação e esforço por parte da família.

Os serviços públicos dão suporte às necessidades da população. A saúde, cuidada pelo Programa de Saúde da Família é levada até às casas pelos Agentes Comunitários de Saúde, é tida como obrigação das mulheres, no sentido de preservá-la no ambiente familiar. Ambiente onde o marido, provedor, se desobriga das atividades domésticas, estando entre elas esse cuidado com a saúde, inclusive a sua própria, sendo a mulher encarregada de descobrir possíveis agravos do parceiro e dos filhos e levar ao conhecimento do serviço de saúde.

Nas conversas que tivemos com as mulheres, o marido é pouco citado, há um misto de medo, respeito $\mathrm{e}$, às vezes indiferença em relação ao parceiro, raras são as vezes em que retratam o marido com afetividade. Nasceram mulheres e precisavam se casar, havendo ou não amor, que se evidenciou em várias falas: "Casei velhinha, mas casei. Casei com 26 anos" (42 anos). Casaram-se cedo e são convictas de que fazem parte da sua condição de mulher e esposa todos os afazeres domésticos, como também o cuidado com o marido 
e, nesse aspecto, não questionam se é certo ou errado: é regra.

$\mathrm{O}$ que aprenderam sobre vida afetiva e conjugal veio, em geral, de informações esquivas da mãe, que afirmam e reafirmam o poderio masculino, a submissão e o dever feminino de ser boa esposa, boa mãe e companheira obediente. As informações adicionais ora são frutos de conversas superficiais com amigas da mesma idade na adolescência, ora da leitura de revistas com conteúdo vago e pouco elucidativo. Algumas vezes, contestam essa condição, mas a resignação finaliza o discurso: "Mãe nunca se preocupou em ensinar nada pra gente e eu nunca me interessei assim mesmo de perguntar a ela não. Primeiro por que eu tinha muita vergonha, e segundo por que ela nunca se abriu também" (22 anos).

O casamento é o objetivo maior dessas mulheres e, por terem conseguido o posto de esposa, diferenciam-se daquelas que ainda não o possuem ou que apresentam comportamentos impróprios de mulheres dignas, sejam mulheres da rua, ou as que praticam sexo fora do casamento. O sexo é visto como mais uma obrigação doméstica da mulher, mas que é, sobretudo, um desejo do marido. É próprio do homem ter "necessidades sexuais" e dever da mulher satisfazê-las, principalmente, sendo esposa e provida pelo parceiro.

Sendo o sexo uma necessidade do homem, as práticas extraconjugais são percebidas como fato natural e esperado dentro da idéia que essas mulheres fazem do universo masculino, pois, mesmo não sendo uma atitude desejada, tornando-se realidade será compreendida pela esposa. Por essas razões, não se confia no parceiro, mas também não há cobranças. Isso foi observado a partir de outra fala, onde justifica possíveis relacionamentos extraconjugais do marido: " ... sabe 'home' como é que é, quando tá viajando, num fica quietinho de maneira nenhuma não. A gente tem obrigação de esperar, mas eles não, né" (37 anos).

Por vezes, o que dizem questionar sobre seus comportamentos fora de casa, é se há cuidado com o sexo da rua, se há ou não o uso da "camisinha" e o incentivo para que exista o uso do preservativo, pois sendo o cuidado com a saúde um dever da mulher, essa se torna apenas mais uma preocupação. Esse discurso se apresenta para nós como elaborado a partir do que se ouve e, muitas vezes, essa preocupação é o reflexo da cobrança dos serviços de saúde que procuram e não necessariamente uma preocupação pessoal com a saúde do parceiro ou com a sua. Conversas acerca de sexo são raras na vida doméstica e quando acontecem são críticas em torno do comportamento do parceiro fora do casamento.
Ainda que existindo essa conversa, o que observamos é que há um desejo por parte da entrevistada de se mostrar coerente com o tema que está sendo discutido, mas que na realidade, o que aparenta é que há um velamento total no tocante a vida sexual do casal, não existindo em nenhum aspecto conversas nesse sentido, mesmo se isso significar preservação ou não da saúde.

Se a saúde é uma questão feminina, nesse contexto saúde e doença são percebidas de acordo com a importância que é dada ao sintoma ou a quem apresenta o sintoma. No caso das crianças, há sempre uma preocupação com "cansaço" e diarréia; para as mulheres, a preocupação é com o exame preventivo e com as intercorrências associadas à gravidez, parto e puerpério. Nesse aspecto, se todas essas condições se mostram favoráveis, não haverá outras preocupações com doenças, salvo existirem pessoas próximas com algum outro mal que inspire cuidado. As doenças alvo de preocupação para essas mulheres são cotidianas, bem definidas e, para elas, próprias do papel social que desempenham. Aliás, essa é uma condição apontada como sendo comum, no que concerne à representação social que se tem dos males que podem ser visualizados como próximos e possíveis de acontecerem.

Doenças mais graves e raras estão distantes de seu contexto, sendo mais comuns a outras pessoas ou grupos, só se tornando próximas em situações específicas e, ainda assim, resguardadas por amplas considerações, como na situação em que uma entrevistada falava de uma vizinha que havia morrido de AIDS. Ela justificava que essa mulher não era da comunidade e que teria ido morar lá quando adoeceu, para que pudesse ser cuidada pela mãe. Nesse caso, foi observado que trazer a doença para uma condição próxima, ou seja, ter sido gerada no mesmo ambiente em que ela também vive, colocaria a AIDS no seu cotidiano, sendo assim, passível de um contato maior e real, o que não é concebido de forma consciente por essas mulheres. É o que Joffe 26 aponta como condição "estrangeira" da doença, onde doenças graves e incuráveis têm sido tratadas historicamente como problema e responsabilidade do "outro".

Quando estimuladas a falarem o que sabem sobre DST e AIDS, como podem adquiri-las ou como podem evitá-las, um universo de conceitos é posto. Um primeiro ponto importante é o fato da (in)variável confiança no marido, que forma um dos pilares que sustentam a certeza da imunidade das mulheres a esses males, mas que ao mesmo tempo deixa lacunas por pedirem ao parceiro para que quando forem "brincar" fora de casa tomem 
cuidados. Mesmo assim, se algum dano sofrerem, vão justificá-lo por ser parte da condição feminina e de esposa.

Poucas vezes, durante o trabalho de campo, o tema "camisinha" foi abordado sem que antes fosse instigado durante a entrevista e em todas as vezes que foi mencionado, o preservativo surgia como método contraceptivo, nunca como barreira de doenças. O que remete ao discurso de Vermelho et al. 15 e de Villela18 onde são levantadas algumas das questões que implicam restrições na solicitação pelo uso da "camisinha", como, segundo as próprias mulheres, sugerir a utilização deste preservativo, que não por contracepção, pode provocar a desconfiança do marido de estar sendo traído ou de se sentir desacreditado pela esposa em suas atitudes extraconjugais. Além disso, foi comum elas afirmarem que os homens não gostam, que é incômodo e que se só tem a elas, não é preciso se prevenirem de doenças. Ademais eles revertem a situação quando dizem que se elas querem é por que pensam em traí-los, como no caso de uma mulher que repetia a fala do marido - que sempre comentava que não andava com mulher nenhuma e que se ela, a esposa, adoecesse, teria sido contaminada por outro, "... por que quem usa camisinha é mulher que gosta de botar ponta no marido, que é pro marido não descobrir".

Comentários acerca de uso de preservativo masculino surgem, mas o que se observa é que pensar a "camisinha" como uma prática cotidiana é muito mais por um ouvir falar que se previnem doenças, que por saber que de fato existem doenças que podem ser prevenidas, pois quando questionadas sobre algum tipo de doença que pode ser evitada através do uso da camisinha, mencionam "doenças de mulher" comuns quando se tem vida sexual ativa, que são visualizadas como um corrimento, um prurido. As doenças sexualmente transmissíveis (DST) e mesmo a AIDS se situam nessas falas dentro de uma abstração, que pode ser percebida como o não reconhecimento dessas doenças como algo real e, se real, possíveis em suas vidas.

Um outro pilar que viabiliza a crença de proteção contra males dessa ordem é a fé irrestrita em Deus. A ligação com o sagrado sempre trouxe conforto e esperança em situações de enfermidade, principalmente para populações menos abastadas economicamente. O discurso de cunho religioso permeia o discurso técnico, justificando as condições de vida, saúde e doença, como responsabilidades divinas e, por assim serem, aceitáveis, não se questionando estruturas históricas, socioeconômicas e políticas que possam determiná-las. Muitas vezes, condições de doenças são percebidas como frutos de apren- dizado a partir de castigos de Deus. Nesse sentido, não é raro se ouvir que se algum mal de qualquer natureza recair sobre determinada pessoa "... é por que Deus quer".

Nenhuma das entrevistadas acredita de forma convicta que pode vir a se infectar por alguma doença de caráter sexual. A confiança no parceiro, a sorte e a fé em Deus acabam por gerar condições de quase imunidade absoluta. E mesmo as que já se sentiram expostas a alguma doença devido ao comportamento do parceiro, resignam-se pelo fato de "homem ser assim mesmo".

Os comentários sobre DST e HIV/AIDS foram poucos, quando surgiam, eram vagos e muitas vezes dúbios. Nos discursos em que algum grau de desconfiança do parceiro era relatado, mesmo considerando a possibilidade de prevenção dessas doenças, a não execução das medidas preventivas era uma regra quase sem exceções. Nesse aspecto, fica a percepção de que o conhecimento que se apresenta sobre HIV/AIDS e DST é superficial ou inexistente.

Poderíamos sugerir que essa situação ocorre por não haver informações que circulem nos ambientes a que essas mulheres têm acesso. O que observamos, porém, é que estarem ou não expostas a essas doenças abrange um outro universo imbuído de fantasias, medos, tabus e pudores, onde não apenas a falta de informações será responsável pelas percepções que serão feitas acerca de prevenção, risco e contaminação/infecção. Esse universo é o das relações sexuais e de gênero, pois se hoje a dinâmica de infecção da AIDS aponta para um número que mostra que, proporcionalmente, mais mulheres com relação conjugal estável se infectam, podemos colocar que tal contaminação acontece principalmente através de relações sexuais, que, em última análise, são ditadas pelas relações de gênero.

Marcadas por concepções enraizadas sobre papéis masculino e feminino, essas mulheres acabam por entenderem certas dinâmicas de vida como lógicas, corretas e imutáveis. A partir desse aspecto, podemos entender como certos comportamentos dos homens permanecem intocados, mesmo quando criticados e, por vezes, envolvidos num desejo de que fossem diferentes. No contexto familiar, essas esposas entendem seu papel como natural e desejado por todas as outras mulheres, sem questionamentos ou críticas explícitas, onde qualquer turbulência que surja na relação é encarada como uma situação prevista. No caso do surgimento de doenças ou afecções associadas à vida sexual, a percepção feita é de que se trata de um problema esperado para mulheres que possuem vida sexual ativa, mesmo se esse agravo surgir em decorrência de relações do 
parceiro fora do casamento, com outras mulheres e, até mesmo, com outros homens, já que o desejo sexual masculino é reconhecido e legitimado como insaciável.

Além disso, foi observado que muitas dessas mulheres desconhecem a etiologia e os modos de contágio/infecção das doenças. É o que acontece com a idéia que fazem da infecção pelo HIV/AIDS, visto que para muitas se prevenir dessa doença é ter regularidade com o exame preventivo, que fazem uma ou duas vezes ao ano, no posto de saúde. Não percebem este agravo como um mal mais importante, que vem sendo estudado ao longo dos anos e que, mesmo assim, permanece incurável.

Percebem o casamento como barreira (mesmo que parcial) para essas doenças, já que se previnem através do Papanicolau e entendem certas doenças como próprias de "mulheres da vida", sendo dessa forma pouco provável que as atinjam, mesmo reconhecendo que o parceiro pode ter relações com essas mulheres. Esse pensamento fica evidente na fala da entrevistada, ao dizer que acha que mulher pode ter mais risco de adoecer se ela for uma mulher "... que transe com um, transe com outro. Aquela que só tem só o dela mesmo, não. E homem é por que o homem é galinha, o homem num pode ver mulé...".

Um outro fator se apresenta como determinante para sua imunidade: a presença da "camisinha", na vida do homem, quando ele tem relações fora do casamento. Algumas mulheres chegam a afirmar que colocam o preservativo na carteira do marido, no intuito dele usar nessas relações clandestinas.

A categoria homossexual é mencionada como alvo provável de infecção, mas sem muita ênfase, já que seria uma categoria, para elas, naturalmente exposta ao HIV/AIDS. Além disso, quando se pensa em homossexual, ou HSH a imagem sugerida é a de travestis e efeminados, descartando-se a possibilidade de homens não possuidores dessas características "ditas de veados" virem a ter alguma relação sexo-afetiva com outro homem. Dessa forma, é improvável para essas mulheres que seus maridos possam ter algum envolvimento dessa natureza, o que pode afastar ainda mais, para elas, a possibilidade real de infecção pelo HIV/AIDS, pela idéia que fazem de quem pode ter o HIV/AIDS.

A partir desses aspectos, podemos sugerir que mulheres casadas, principalmente as que apresentam pouca escolaridade e possuem nível socioeconômico baixo, tendem a reconhecer o HIV/AIDS como uma possibilidade distante de suas vidas. Essas mulheres muitas vezes, encontram-se envolvidas em definições e conceitos que pouco esclarecem e mais confundem a percepção que têm de risco de contaminação /infecção, atribuindo a outras pessoas e grupos como as prostitutas e HSH - serem mais susceptíveis a infecções dessa ordem.

O que nos permite entender, a partir disso, é que a representação social que mulheres, nas condições citadas, têm da AIDS, da infecção pelo HIV, acaba por propiciar um aumento da sua vulnerabilidade frente à infecção, já que o entendimento que fazem das condições de infecção pelo vírus e posterior desenvolvimento da doença acaba por incrementar a sua exposição aos comportamentos de risco.

Mesmo com discurso permeado de reservas, essas mulheres entendem como sendo distante e inacessível uma possível infecção pelo HIV/AIDS. Apontam tais discursos, primeiro, por não deterem completamente o conhecimento de como se processa a infecção e, dessa forma, não reconhecerem formas de prevenção e, mesmo reconhecendo, acabam por subestimá-las. Segundo, pessoas como prováveis fontes da infecção estão distantes de suas vidas, fazendo parte de um universo que não cruza com o seu, que são principalmente as "mulheres da vida" e os "gays". Terceiro, não concebem como possível o fato de que doenças, às vezes mencionadas como "doenças do mundo", possam penetrar num ambiente familiar e, principalmente, se protegido por Deus.

A representação social de mulheres casadas, com privações materiais, e pouca escolaridade, não difere de forma importante daquela apresentada pelo comum das pessoas em se tratando de doenças infecciosas, graves e raras. O fato é que a maioria dos indivíduos, por qualquer justificativa que dêem, não se vê alvo de nenhum mal, visto que ele sempre se mostra distante de seus ambientes sociais, atingindo àqueles que possuem características e comportamentos distintos dos seus.

Quando, em alguma situação peculiar, algum mal dessa natureza se insere no meio em que vivem, esse fato é fundamentado por argumentos que responsabilizem o comportamento individual da pessoa afetada e possíveis lugares que freqüenta como os responsáveis pela condição de doença. Assim, o mal torna-se importado, nunca gerado naquele meio, ou como definiria Joffe, 26 como uma condição estrangeira.

Finalmente, entendemos que essa condição incrementa a vulnerabilidade do grupo que compõe nosso estudo. Pensar a AIDS como condição própria de outras pessoas e, quando junto aos seus, vista como uma condição importada, viabiliza o trânsito da epidemia de forma silenciosa e imperceptível entre suas vidas, só se tornando real quando transformada em um mal irremediável, sendo assim, arremessadas à condição de mais um número nas 
estatísticas que apontam para a mulher como principal alvo de infecção hoje pelo HIV/AIDS.

Essa forma de perceber a AIDS, como distante, inacessível, do "outro" e, senão do "outro", advinda dele, pode ser compreendida pela necessidade, própria do homem, em se proteger e só, retorica- mente, se reconhecer como mortal, passível de vivenciar dores. Além disso, nosso universo de mulheres entrevistadas construiu um imaginário que asseverava sua imunidade diante do HIV/AIDS, que poderia ser mais acentuada caso se recolhessem ainda mais dentro do matrimônio.

\section{Referências}

1. Ayres JRCM, Calazans GJ, França Jr I. 1997. Aids, vulnerabilidade e prevenção. In: Seminário saúde reprodutiva em tempos de AIDS; 1997, nov. 7 a 9; Rio de Janeiro, RJ. Rio de Janeiro: ABIA; 1997. p. 20-37.

2. Bastos C, Galvão J, Parker R, Pedrosa JT. A AIDS no Brasil 1982-1992. 2. ed. Rio de Janeiro: Relume-Dumará; 1994.

3. Parker R.. Na contramão da AIDS: sexualidade, intervenção e política. Rio de Janeiro: ABIA; 2000.

4. Daniel HE, Parker R. AIDS, a terceira epidemia: ensaios e tentativas. São Paulo: Iglu; 1991.

5. Galvão J. AIDS no Brasil: a agenda de construção de uma epidemia. Rio de Janeiro: ABIA; 2000.

6. Guimarães CD. Mulheres, homens e AIDS: o visível e o invisível. In: Bastos C, Galvão J, Parker R, Pedrosa JS, organizadores. A AIDS no Brasil: 1982-1992. 1994. 2. ed. Rio de Janeiro: Relume-Dumará: 1994. p. 217-230.

7. Boletim Epidemiológico - AIDS; 2001/2002; Ano XV (1): 5-9.

8. Ministério da Saúde. 2001. ABIAIDS. Disponível em $<$ http://www.abiaids.gov.br/tabelas $>$ [2002 Ago 8].

9. Berer M. Mulheres e HIV/AIDS: um livro sobre recursos internacionais. São Paulo: Brasiliense: 1997.

10. Heilborn ML Ser ou estar homossexual: dilemas de construção de identidade social. In: Barbosa RM, Parker R, organizadores. Sexualidades brasileiras. Rio de Janeiro: Relume-Dumará; 1996. p. 136-45.

11. Ministério da Saúde. Coordenação Nacional de DST/AIDS Fios da vida: tecendo o feminino em tempos de AIDS Brasília (DF); 2000.

12. Knauth DR. Subjetividade feminina e soropositividade. In: Barbosa RM, Parker R organizadores. Sexualidades pelo avesso: direitos, identidade e poder. São Paulo: Ed. 34; 1999. p. 121-36.

13. Ayres JRCM, Calazans GJ, Saletti Filho H. Vulnerabilidade e prevenção em tempos de AIDS. In: Barbosa R e Parker R, organizador. Sexualidades pelo avesso: direitos, identidade e poder. São Paulo: Editora 34; 1999. p. 49-79.

14. Campos RCP. AIDS: trajetórias afetivo-sexuais das mulheres. In: Bruschini C, Hollanda HB. Horizontes plurais: novos estudos de gênero no Brasil. São Paulo: Ed. 34; 1998. p. 85-109.

15. Vermelho LL, Simões-Barbosa RH, Nogueira SA. Mulheres com AIDS: desvendando histórias de risco. Cad Saúde Pública 1999; 15: p. 369-79.

16. Parker R. Corpos, prazeres e paixões: a cultura sexual no Brasil contemporâneo. São Paulo: Nova Cultural; 2000.

17. Barbosa RM. Negociação sexual ou sexo negociado: poder, gênero e sexualidade em tempos de AIDS. In: Barbosa RM, Parker R, organizadores. Sexualidades pelo avesso: direitos, identidade e poder. São Paulo: Ed. 34; 1999. p. 73-88.

18. Villela WV. Prevenção do HIV/AIDS, gênero e sexualidade. In: Barbosa RME, Parker $\mathrm{R}$ organizadores. Sexualidades pelo avesso: direitos, identidade e poder. São Paulo: Ed. 34; 1999. p. 199-213.

19. Barbosa RM, Villela WV. A trajetória feminina da AIDS. In: Galvão J, Parker R, organizadores. Quebrando o silêncio: mulheres e AIDS no Brasil. Rio de Janeiro: Relume-Dumará: ABIA; 1996. p. 17-32.

20. Nobrega SM. O que é representação social [tese doutorado]. Paris: Ecole Études en Ciences Sociales; 1990.

21. Jovechlovitch S. Representações sociais e esfera pública: a construção simbólica dos espaços públicos do Brasil. Petrópolis: Vozes; 2000.

22. Santos MFS. Representação social e identidade. In: Moreira AS, Oliveira DC, organizadores. Estudos interdisciplinares de representação social. Goiana: Ed. AB; 1998. p. 154-63.

23. Moscovici S. A representação social da psicanálise. Rio de Janeiro: Zahar; 1978.

24. Farr RM. Representações socias: a teoria e sua história. In: Jovechlovitch S, Guareschi P, organizadores. Textos em representações sociais. Petrópolis: Vozes; 1995. p. 31-59.

25. Minayo MCS. O desafio do conhecimento - Pesquisa qualitativa em saúde. 7. ed. São Paulo: Hucitec; 2000.

26. Joffe H. Eu não, meu grupo não: representações sociais transculturais da AIDS. In: Jovechlovitch S, Guareschi P, organizadores. Textos em representação. 4.ed. Petrópolis: Vozes, 1994. p. 296-308.

Recebido em 11 de junho de 2004

Versão final apresentada em 13 de dezembro de 2004

Aprovado em 14 de janeiro de 2005 